ODD, but benefits at 24 months had diminished when compared to outcome at 10 months. Combination medication and behavior therapy was not superior to medical management alone, Results of behavior therapy were not significantly different from routine community care. The benefits of intensive medical management of ADHD symptoms extend 10 months beyond the two-year treatment phase, but the effects diminish over time. (NIMH, 2004). The AAP Committee on Quality Improvement concluded that: (1) ADHD should be managed as a chronic condition, (2) stimulant medications are beneficial and different medications are equally effective, (3) behavioral therapy is minimally effective but only in combination with medication, and (4) education and counseling of patient and family are necessary adjuncts to drug therapy (Brown RT et al. Pediatrics 2005;115:e749-e757; Millichap JG. ADHD Handbook. A Physician's Guide to ADHD: New York, Springer, 2010).

\title{
EEG ABNORMALITIES AND EPILEPSY IN AUTISTIC SPECTRUM DISORDERS
}

EEG abnormalities and epilepsy in 57 children ( $86 \%$ male), mean age $82+/-36.2$ months, with autistic spectrum disorders and their association with clinical, psychiatric, developmental, and familial risk factors were examined at Marmara and Acibadem Universities, Istanbul, Turkey. A diagnosis of autism was made in 68\%, PDD in 26\%, and high-functioning autism in 5\%. EEG recordings were 1 hour, sleep and/or awake. Sleep only EEGs were obtained in $86 \%$ of patients; $95 \%$ with autism, $60 \%$ with PDD, and $100 \%$ for those with high functioning autism. Awake EEGs were obtained in $40 \%$ of children with PDD but only $5 \%$ of those with autism. Interictal epileptiform EEG abnormalities (IIEAs) were present in $24.6 \% \quad(n=14)$, and epilepsy was diagnosed in $14.2 \%(n=8$, complex partial in 4). IIEAs were associated with the diagnosis of epilepsy ( $\mathrm{P}=0.0001$ ), hyperactive behavior (Childhood Autism Rating Scale Activity scores, $\mathrm{P}=0.047)$, and a history of asthma and allergy $(\mathrm{P}=0.044)$. Epilepsy was associated with a family history of epilepsy $(\mathrm{P}=0.049)$ and psychiatric problems in the mother during pregnancy $(\mathrm{P}=0.0026)$. Eleven patients were taking AEDs, in 8 for epilepsy ( 4 in remission) and 3 for behavioral symptoms. Psychotropic medication was used in $44 \%$ of patients, risperidone in one half of these. (Ekinci O, Arman AR, Isik U, Bez Y, Berkem M. EEG abnormalities and epilepsy in autistic spectrum disorders: clinical and familial correlates. Epilepsy Behav Feb 2010;17:178-182). (Respond: Dr Ozalp Ekinci. E-mail: ozalpekinci@yahoo.com).

COMMENT. Studies cited by the authors show that the frequency of epilepsy in autism varies from $4 \%$ to $42 \%$, and that of interictal epileptiform EEG abnormalities in ASD without seizures is between $6 \%$ and $74 \%$. (eg. Tuchman R, Rapin I. Lancet Neurol 2002;1:352-8; Olsson I, Steffenberg S, Gillberg C. Arch Neurol 1988;45:666-8). 